\title{
Medidas morfométricas de fêmeas e machos de Oncideres dejeani Thompson, 1868 (Coleoptera: Cerambycidae)
}

\author{
Morphometric measurements of males and females of Oncideres dejeani Thompson, 1868 \\ (Coleoptera: Cerambycidae)
}

\author{
Rita de Cássia Andrade dos Santos Seffrin ${ }^{1}$ Ervandil Corrêa Costa ${ }^{2}$ \\ Mara Rúbia Machado Couto ${ }^{3}$ Sidinei José Lopes ${ }^{4}$
}

\begin{abstract}
O objetivo deste trabalho foi identificar aspectos morfológicos de Oncideres dejeani que possibilitem a diferenciação sexual destes insetos. Dados da morfometria de 25 casais de insetos obtidos com auxílio de um microscópio estereoscópico e de um paquímetro mostram que o comprimento e a largura dos fêmures dos exemplares machos são menores do que os dos exemplares fêmeas, porém apresentam antenas maiores, havendo uma diferenciação no tamanho das antenas após o quarto antenômero, pelo teste de Mann-Whitney, em 5\% de probabilidade de erro. Fêmeas e machos também apresentaram diferenças significativas quanto às medidas de comprimento do élitro, à largura entre os tubérculos, à largura apical do élitro e à largura posterior do protórax. Pela praticidade de obtenção, as medidas do tamanho do corpo e do comprimento de antenas podem ser consideradas suficientes como dados morfométricos de diferenciação sexual desta espécie.
\end{abstract}

Palavras-chave: acácia-negra, serrador, besouro.

\section{ABSTRACT}

The objective of this work was to identify morfologycal aspects of Oncideres dejeani that helps the sexual differentiation of this species. Morphometrics data of 25 couples were analysed with a stereo microscope and pachimeter indicated that femur length and width of male individuals were smaller than on the females however the antennas were larger and there is a differentiation on the antennas length after the

\begin{abstract}
forth antennomeres as indicated by the Mann-Whitney test at $5 \%$ error probability. Female and male presented significant differences regarding elytra length, width between tubercle, apical width of elytra of hind prothoracic. For their facility in being taken, the measurements of body size and antennae length can be considered enough as morfologycal data hat can be used for sexual differentiation of this species.
\end{abstract}

Key words: black wattle, sawyer, beetle.

A acácia-negra (Acacia mearnsii De Wild ) é uma das essências florestais mais importantes do Rio Grande do Sul por fornecer a casca (tanino) e madeira para uso doméstico e industrial. Contudo, pode ter sua produção afetada pelo ataque de Cerambicídeos, que são considerados os principais causadores de danos à cultura. Dentre os insetos prejudiciais, destacam-se os besouros cortadores de galhos, conhecidos vulgarmente por serradores, que, devido a sua importância, foram alvo, inclusive de uma legislação específica para o seu controle (BAUCKE, 1958). A distribuição geográfica das espécies de Oncideres no Brasil foi estudada por VULCANO \& PEREIRA (1978) e LINK \& COSTA $(1988,1993)$, sendo registrada sua ocorrência na região de Santa Maria, RS , por LINK \& COSTA(1988).

\footnotetext{
${ }^{1}$ Programa de Pós-graduação em Agronomia, Departamento de Defesa Fitossanitária, Universidade Federal de Santa Maria (UFSM), 97105-900, Santa Maria, RS, Brasil. E-mail: rsseffrin@mail.ufsm.br.

${ }^{2}$ Departamento Defesa Fitossanitária, UFSM, 97105-900, Santa Maria, RS, Brasil. E-mail: ecosta@ccr.ufsm.br.

${ }^{3}$ Programa de Pós-graduação em Estatística e Modelagem Quantitativa, Departamento de Estatística, UFSM. 97105-900, Santa Maria, RS, Brasil. E-mail: mararubiacouto@hotmail.com.

${ }^{4}$ Departamento de Fitotecnia, UFSM, 97105-900, Santa Maria, RS, Brasil. E-mail: sjlopes@pop.com.br. Autor para correspondência.
} 
Além da acácia-negra, os serradores provocam danos em mais de 50 espécies botânicas no Brasil (SILVA et al., 1968), quando cultivadas em bosques homogêneos, pois em ambiente natural, em equilíbrio, verifica-se que a diversidade das espécies de plantas, aliadas à existência de um complexo de inimigos naturais, mantêm os insetos em baixo nível populacional (BAUCKE, 1958; VULCANO \& PEREIRA, 1978). Também são consideradas pragas importantes por apresentarem um grande número de plantas hospedeiras, porém as informações existentes sobre a biologia de serradores são escassas na literatura (VULCANO \& PEREIRA, 1978).

O tamanho do corpo de espécies de insetos pertencentes à família Cerambycidae tem sido o mais utilizado na diferenciação do sexo, cuja finalidade é auxiliar futuras pesquisas de controle deste inseto. Assim, o objetivo deste trabalho foi identificar aspectos morfológicos de Oncideres dejeani que possibilitem a diferenciação sexual destes insetos.

No período de 1998 a 2000, foram coletados insetos adultos de Oncideres dejeani Thompson, 1868 (Coleóptera: Cerambycidae) em Anadenanthera macrocarpa, Lithraea brasiliensis e Sebastiania brasiliensis, nos municípios de Santa Maria e São Sepé, Rio Grande do Sul.

Os insetos foram mantidos no Laboratório de Entomologia do Departamento de Defesa Fitossanitária da Universidade Federal de Santa Maria, onde se procedeu à mensuração de 25 insetos adultos machos e de 25 fêmeas de Oncideres dejeani (Coleoptera: Cerambycidae), totalizando 23 medidas do corpo de cada inseto. O comprimento total do corpo (CC) e o comprimento do élitro (CE) foram medidos com o auxílio de um paquímetro. As medidas de largura anterior do protórax (LAP), largura entre os tubérculos (LET), largura posterior do protórax (LPP), largura apical do élitro (LAE), comprimento do escapo direito (CED), comprimento do pedicelo direito (CPD), comprimento dos fêmures (CF1, CF2 e CF3), largura do fêmures (LF1, LF2 e LF3) e comprimento dos nove antenômeros foram realizadas com auxílio de um microscópio estereoscópico com micrômetro ocular, aferido através de lâmina micrométrica com precisão de $0,01 \mathrm{~mm}$, totalizando 1150 medições. Em seguida, realizou-se o teste U de Mann-Whitney para comparar as diferenças de medidas entre machos e fêmeas, em nível de $5 \%$ de probabilidade de erro. Para os nove antenômeros, também foram representadas graficamente as diferenças de comprimento entre fêmeas e machos, com a visualização da dispersão, simetria e outliers através da técnica de box plot.

Observa-se que, em geral, as medidas do corpo, do comprimento e da largura dos fêmures dos exemplares machos são menores do que as dos exemplares fêmeas (Tabela 1). Porém, deve-se ressaltar que a amplitude de variação do comprimento do corpo das fêmeas $(14,30 \mathrm{~mm})$ é maior do que a dos machos (9,05mm). Fêmeas apresentaram comprimento do corpo maior que dos machos, e diferenças significativas também foram verificadas quanto às medidas de comprimento do élitro, da largura entre os tubérculos, da largura apical do élitro e da largura posterior do protórax.

Tabela 1 - Valores mínimos (mín.), máximos (máx.), em mm, e estatística Z da aproximação normal do teste $\mathrm{U}$ de Mann-Whitney das medidas morfométricas de machos ( $\delta$ ) e de fềmeas (q) de Oncideres dejeani. Santa Maria-RS, 2002.

\begin{tabular}{|c|c|c|c|c|c|c|}
\hline Medidas & Mín. $\delta$ & Máx. $\delta$ & Mín. 9 & Máx.? & Z & \\
\hline Comprimento do corpo & 15,85 & 24,9 & 11,70 & 26,00 & $-2,82^{*}$ & $q>$ \\
\hline Comprimento do élitro & 11,60 & 18,4 & 13,35 & 21,55 & $-3,78^{*}$ & Q> \\
\hline Largura anterior do protórax & 3,50 & 6,10 & 4,00 & 9,90 & $-4,89^{*}$ & $q>$ \\
\hline Largura entre os tubérculos & 4,00 & 6,90 & 4,40 & 7,90 & $-3,60^{*}$ & $q>$ \\
\hline Largura posterior do protórax & 3,30 & 5,40 & 4,05 & 9,40 & $-4,71^{*}$ & $q>$ \\
\hline Largura apical do élitro & 5,90 & 9,20 & 6,80 & 10,10 & $-4,16^{*}$ & $q>$ \\
\hline Comprimento do escapo direito & 2,70 & 4,30 & 2,80 & 4,05 & $1,92^{\mathrm{ns}}$ & - \\
\hline Comprimento do pedicelo direito & 0,45 & 0,60 & 0,45 & 0,60 & $0,55^{\mathrm{ns}}$ & - \\
\hline Comprimento do fêmur 1 & 3,75 & 6,10 & 3,95 & 6,40 & $-0,90^{\text {ns }}$ & - \\
\hline Comprimento do fêmur 2 & 3,45 & 5,90 & 3,50 & 6,20 & $-2,44^{*}$ & $q>$ \\
\hline Comprimento do fềmur 3 & 3,20 & 5,20 & 2,75 & 5,70 & $-3,20^{*}$ & $q>$ \\
\hline Largura do fềmur 1 & 1,20 & 1,70 & 1,25 & 1,90 & $-4,55^{*}$ & $q>$ \\
\hline Largura do fêmur 2 & 1,10 & 1,70 & 1,25 & 1,90 & $-4,40^{*}$ & Q> \\
\hline Largura do fêmur 3 & 1,05 & 1,70 & 1,25 & 1,90 & $-4,26^{*}$ & $q>$ \\
\hline
\end{tabular}

* diferença significativa em $5 \%$ de erro; ns diferença não significativa; $q>$ medida das fềmeas maior do que dos machos. 
Por outro lado, verificou-se que apenas algumas variáveis não diferiram significativamente entre machos e fêmeas, sendo elas: a medida do comprimento do fêmur 1 , do comprimento do escapo direito e do comprimento do pedicelo direito. Em trabalho com morfometria de um inseto da mesma família Cerambycidae e da ordem Coleoptera (Hedypathes betulinus Klug,1825), CASSANELLO (1993) observou que o comprimento do escapo e o comprimento do pedicelo são maiores nos insetos machos.

Com relação aos

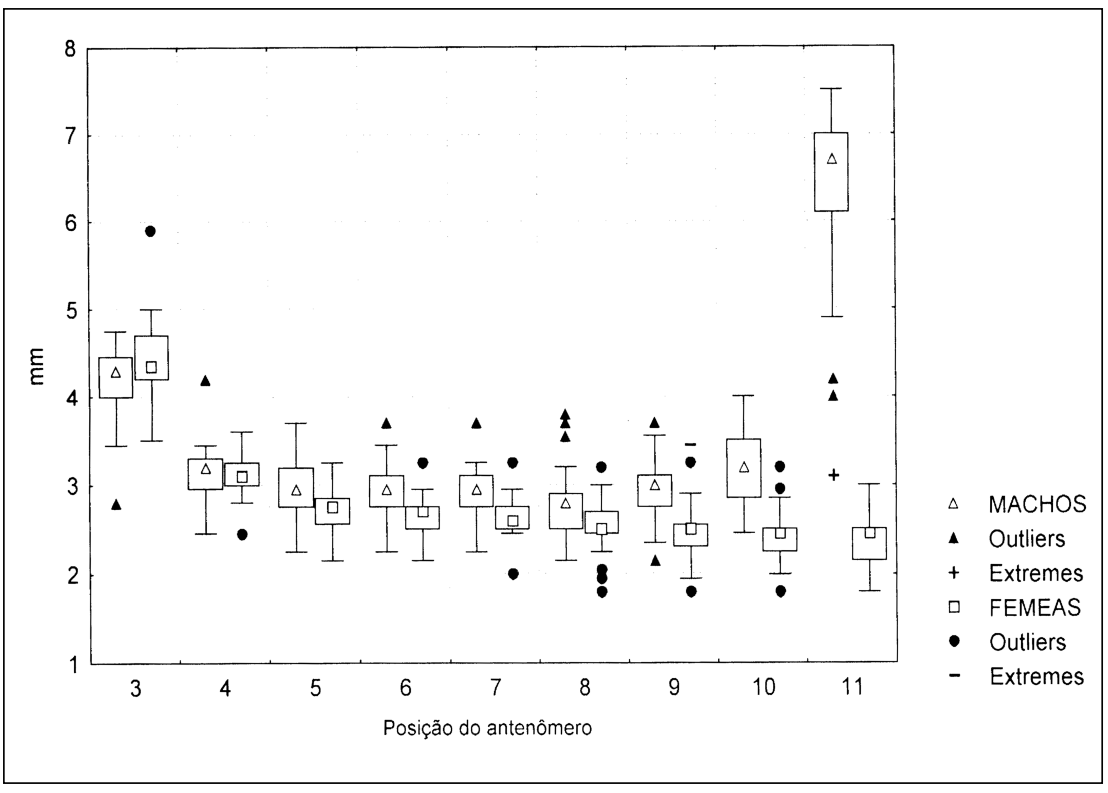

Figura 1 - Box plot para medidas (em mm) de nove antenômeros de machos e de fêmeas de Oncideres dejeani. Santa Maria-RS, 2002. antenômeros 3 e 4 , não

houve diferença significativa pelo teste de MannWhitney, em 5\% de probabilidade de erro. Já para os demais, verificou-se que os machos apresentaram antenômeros maiores do que as fêmeas, sendo observado que, para os antenômeros 10 e 11, existe uma diferença maior do que para os demais antenômeros entre machos e fêmeas (Figura 1).

É possível fazer a diferenciação sexual de Oncideres dejeani pelo comprimento total das antenas, ou seja, pela soma dos comprimentos do escapo, do pedicelo e do flagelo (total do comprimento dos antenômeros). O maior comprimento das antenas nos insetos machos também foi observado por PEDROSAMACEDO et al. (1993) em outra espécie da família Cerambycidae, ordem Coleoptera: a Phoracantha semipunctata Fab., 1775.

Quando não existem diferenças estruturais, de maneira geral, entre as antenas de machos e fêmeas, somente no comprimento das mesmas, como é o caso da maioria dos insetos da família Cerambycidae, ordem Coleoptera HANKS et al. (1996) relatam que o sucesso de acasalamentos depende da taxa de deslocamento e da extensão que atingem as antenas dos machos, portanto, as fêmeas não teriam vantagens em possuir antenas maiores, sugerindo uma explicação evolutiva para o dimorfismo sexual.

O comprimento do corpo dos machos de Oncideres dijeani variou de aproximadamente 16 a $25 \mathrm{~mm}$, sendo um pouco maior do que o dos machos de
Oncideres saga, que varia de 13 a 20mm (FURB, 2005). Em ambos porém, a antena dos insetos machos é mais longa do que o corpo, e o corpo menor do que o da fêmea. Insetos fêmeas pertencentes ao gênero Satipoella (Coleoptera, Cerambycidae, Lamiinae) também apresentam antenas mais curtas do que o corpo, enquanto que, nos machos, as antenas ultrapassam o ápice elitral em pelo menos dois antenômeros (JULIO, 2003).

Dados da morfometria de insetos machos e fêmeas de Oncideres dejeani indicam que o tamanho do corpo e o comprimento das antenas são os principais parâmetros para identificar o sexo desta espécie.

\section{REFERÊNCIAS}

BAUCKE, O. Biologia e controle do serrador da acácia negra. Porto Alegre: Secretaria da Agricultura, Indústria e Comércio, 1958. 59p.

CASSANELLO, A.M.L. Ciclo de vida e aspectos morfológicos de Hedypathes betulinus (Klug, 1825) (Coleoptera, Cerambycidae), Lamiinae), broca-da-ervamate (Ilex paraguariensis St. Hil.). 1993. 59f. Dissertação (Mestrado em Entomologia)- Universidade Federal do Paraná.

FURB. Monitoramento Florestal. Capturado em 8 set. 2005. Online. Disponível na Internet http://www.furb.monitoramento florestal/pragas.html.

HANKS, L.M. et al. Mating behavior of the eucalyptus longhorned borer (Coleoptera: Cerambycidae) and the adaptive significance of long "horns". Journal of Insect Behavior, v. 9, n. 3, p. 383-394. 1996. 
JULIO, C. E. A. Revision of the genus Satipoella (Coleoptera, Cerambycidae, Lamiinae). Iheringia, Série Zoologia, v. 93, n.2, p. 143-142. 2003.

LINK, D.; COSTA, E. C. Freqüência de corte e diâmetro dos galhos cortados por duas espécies de Oncideres em bosque de angico e eucalipto, em Santa Maria - RS. Revista do Centro de Ciências Rurais, Santa Maria, v.18, n.2, p.119-124, 1988.

LINK, D.; COSTA, E. C. Aspectos da biologia de Oncideres impluviata e de $\boldsymbol{O}$. captiosa em Santa Maria - RS. (Coleoptera: Cerambycidae). Ciência Florestal, Santa Maria, v.3, n.1, p.7784, 1993.
PEDROSA-MACEDO, J. H. et al. Manual de pragas em Florestas. Viçosa: IPEF, 1993. 111p.

SILVA, A. G. A et al.. Quarto catálogo dos insetos que vivem nas plantas do Brasil, seus parasitos e predadores. Rio de Janeiro: Ministério da Agicultura, 1968, parte II, tomo 1, p.622.

VULCANO, M. A.; PEREIRA, F. S.. O gênero Oncideres Serville, 1835 no sul do país e países limítrofes: séria praga dos pomares e da silvicultura. Studia Entomologica, Petrópolis, n.20, p.177220, 1978. 